\title{
Periprostatic fat measured on computed tomography as a marker for prostate cancer aggressiveness
}

\author{
Joep G. H. van Roermund • Gijsbert H. Bol • \\ J. Alfred Witjes · J. L. H. Ruud Bosch • \\ Lambertus A. Kiemeney $\cdot$ Marco van Vulpen
}

Received: 16 July 2009 / Accepted: 7 December 2009 / Published online: 22 December 2009

(C) The Author(s) 2009. This article is published with open access at Springerlink.com

\begin{abstract}
Objective Several reports found that obesity was associated with prostate cancer (PC) aggressiveness among men treated with radical prostatectomy or radiotherapy. Studies concerning this issue have basically relied on body mass index (BMI), as a marker for general obesity. Because visceral fat is the most metabolic active fat, we sought to evaluate if periprostatic fat measured on a computed tomography (CT) is a better marker than BMI to predict PC aggressiveness in a Dutch population who underwent brachytherapy for localized PC.

Patients and methods Of the 902 patients who underwent brachytherapy, $725 \mathrm{CT}$ scans were available. Subcutaneous fat thickness (CFT), periprostatic fat area $\left(\mathrm{cm}^{2}\right)$ and fatdensity (\%) were determined on the CT scan. Patients were stratified into three groups: $<25,25-75$ and $>75$ percentile of the fat-density. Associations between the three fatdensity subgroups and BMI and PC aggressiveness were examined.
\end{abstract}

J. G. H. van Roermund $(\bowtie) \cdot$ J. L. H. Ruud Bosch

Department of Urology, University Medical Center Utrecht, PO Box 85500, 3508 GA Utrecht, The Netherlands

e-mail: j.g.h.vanroermund@umcutrecht.nl

G. H. Bol · M. van Vulpen

Department of Radiation Oncology,

University Medical Center Utrecht, Utrecht, The Netherlands

J. Alfred Witjes · L. A. Kiemeney

Department of Urology, Radboud University Nijmegen

Medical Centre, Nijmegen, The Netherlands

L. A. Kiemeney

Department of Epidemiology and Biostatistics,

Radboud University Nijmegen Medical Centre,

Nijmegen, The Netherlands
Results 237 patients were classified as having normal weight $(37.2 \%), 320$ as overweight $(50.2 \%)$ and 80 as obese $(12.6 \%)$. There was a strong significant association between BMI and fat-density and CFT. The strongest correlation was seen between BMI and CFT (Pearson $r$ coefficient $=0.71)$. Logistic regression analysis revealed no statistically significant association between the different fat measurements and the risk of having a high-risk disease.

Conclusions Periprostatic fat and fat-density as measured with CT were not correlated with PC aggressiveness in patients receiving brachytherapy. However, $31 \%$ of the patients with a normal BMI had a fat-density of $>75$ percentile of the periprostatic fat-density.

Keywords Obesity - Visceral fat · Prostate cancer . Body mass index (BMI) $\cdot$ Brachytherapy

\section{Introduction}

Obesity and prostate cancer (PC) are two major health concerns. On one hand, obesity is a rapidly growing worldwide epidemic and it increases the risk of several chronic diseases and certain cancers $[1,2]$. On the other hand, PC is diagnosed more often in the prostate-specific antigen (PSA) era and the disease is often diagnosed at a localized stage suitable for curative treatment [3].

The relationship between obesity and PC is debated, with studies finding an inverse, a linear correlation with PC, or no relation at all [4-6]. However, several studies found a link between obesity and disease aggressiveness [7-9].

Recently, the classical perception of adipose tissue as a storage place of fatty acids has been replaced by the notion that adipose tissue produces a large number of hormones and cytokines, e.g., tumour necrosis factor- $\alpha$, interleukin- 6 , 
leptin and adiponectin [10]. The exact role of these cytokines in prostate carcinogenesis, however, is not known. Most of the studies that investigated the role of obesity on PC used body mass index (BMI, the weight in kilograms divided by the squared height in meters) as a marker of general obesity. Although there is a strong correlation between BMI and waist-circumference (WCF), the most metabolic active fat is the abdominal visceral fat and a better way to measure this is by waist-hip ratio or WCF. Therefore, WCF as an indicator of abdominal fat may be a better predictor for PC risk than BMI alone, especially in men with a low BMI. Computed tomography (CT) is another technique which measures visceral fat even more accurately $[11,12]$.

The aim of this study was to investigate whether periprostatic fat, measured on a CT, is a better marker for PC aggressiveness in patients who underwent brachytherapy for localized PC compared to BMI. We also evaluated the relation between BMI and different fat measurements. To the best of our knowledge such a study has never been performed.

\section{Patients and methods}

\section{Patients}

Between April 2004 and August 2008, 902 patients with biopsy-proven localized PC (stage cT1 or cT2) were treated with transrectal ultrasonography guided transperineal permanent mono brachytherapy at the department of Radiotherapy, University Medical Center Utrecht, The Netherlands. Due to the very short follow-up of this cohort of men we only focused on PC baseline characteristics. Patients underwent clinical staging by medical history, digital rectal examination and serum PSA measurement. Bone scans were obtained and pelvic lymph node dissection was performed when clinically indicated. A CT was performed 1 day after the brachytherapy to determine specific dose constraints. The CT was not performed in 153 patients and in 24 patients the quality of the $\mathrm{CT}$ was poor due to hip prostheses. This resulted in a study population of 725 men.

Because different risk classifications are used in the literature we decided to use two different risk classifications, one according to Ash et al. [13] and the other according to D'Amico et al. [14]. Tumour stage was described according to the 2002, TNM, American Joint Committee on Cancer system.

Fat measurement

Preoperative height and weight data were collected retrospectively by reviewing anaesthesia records. The BMI
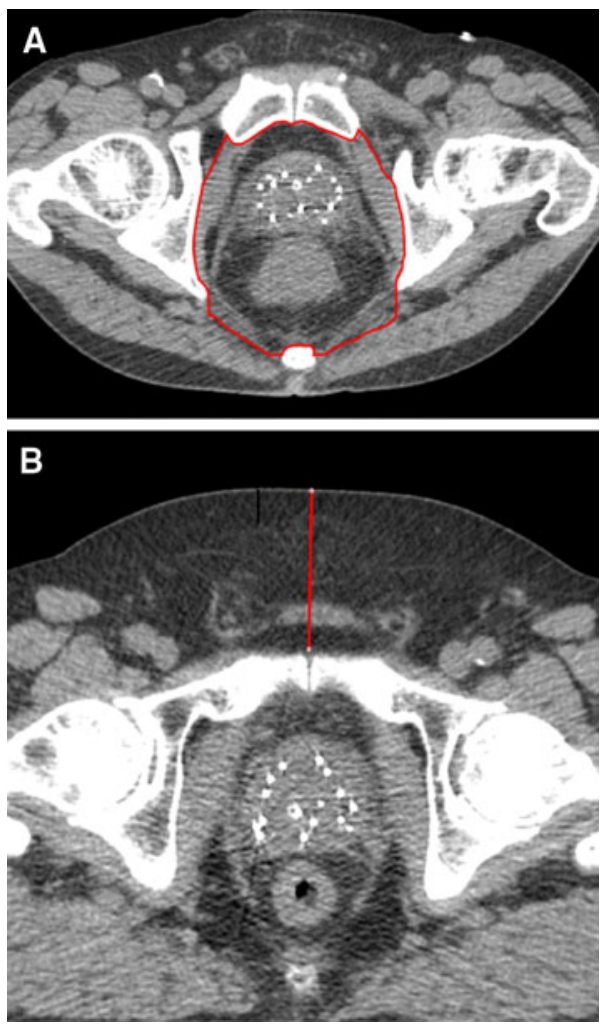

Fig. 1 Images demonstrate our method for determining visceral fat distribution and subcutaneous fat thickness on a CT scan. a Transverse section is made at the level of the caput femoris and greater trochanter of the femur. The red line, outlines the total contour area $\left(\mathrm{cm}^{2}\right)$, in which attenuation is measured. The line is drawn at the back side of the pubic bone, lateral border of obturatorius internus muscle, anterior side of the gluteus maximus muscle and coccyx bone. Within the region of interest the periprostatic fat area $\left(\mathrm{cm}^{2}\right)$ and the fat-density $(\%)$ was calculated. b Transverse section is made at the level of superior pubic ramus. The red line outlines the subcutaneous fat thickness by which the distance between the skin and pubic bone is measured. $(\mathrm{cm})$

$\left(\mathrm{kg} / \mathrm{m}^{2}\right)$ was calculated and stratified into three groups according to the WHO, i.e. normal weight $(<25)$, overweight $(25-30)$ and obese $(\geq 30)$. Only one patient had a BMI value of $<18.5 \mathrm{~kg} / \mathrm{m}^{2}$, this patient was included in the normal weight group. The CT's were acquired on a single slice CT (Aura, Philips Medical Systems, Best, The Netherlands), and had an in-plane slice resolution of $0.49 \times 0.49 \mathrm{~mm}$ with a slice thickness of $3 \mathrm{~mm}$. We used an in-house developed software tool for delineation of the pelvic fat region and the measurement of the subcutaneous fat thickness (CFT, see Fig. 1) [15].

Because there are no comparable studies available we chose to delineate along established lines (see Fig. 1). The fat contained within the delineated contours of the CT, is segmented by thresholding on the Hounsfield Units (HU). We differentiated between fat $(-190$ to $-30 \mathrm{HU})$, air $(<-500 \mathrm{HU})$ and other soft tissue types [16]. Since the delineated contours did not contain bony structures, we did 
not include a threshold for segmenting the bones separately. The total contour area $\left(\mathrm{cm}^{2}\right)$ was calculated by the total number of voxels within the contour minus the number of air voxels and the periprostatic fat area $\left(\mathrm{cm}^{2}\right)$ by just counting 'fat' voxels within the total contour area. The fat-density (\%) was calculated by dividing periprostatic fat by the total contour area.

Patients were stratified into three groups: $<25$ percentile (group 1), between 25 and 75 percentile (group 2) and $>75$ percentile (group 3 ) of the fat-density.

\section{Statistical analysis}

Associations between the predefined three fat-density subgroups and clinical or pathological characteristics were examined by Chi-square tests in case of categorical characteristics and Kruskal-Wallis tests in case of continuous characteristics. The Pearson correlation coefficient was used to quantify correlations between BMI and the different fat measurements. Binary logistic regression analyses were performed to evaluate the independent effect of each variable on the risk of having high-risk disease versus low or intermediate risk (according to Ash et al. [13] and D' Amico et al. [14]).

Differences were considered to be statistically significant if $p<0.05$. Data were analysed using SPSS for Windows (version 15.0).

\section{Results}

The median age (range), BMI and fat-density at the time of brachytherapy was 66 years $(45-81), 25.8 \mathrm{~kg} / \mathrm{m}^{2}$ (17.6$56.8)$ and $31.8 \%$ (10.0-52.2), respectively. In 88 (12\%) patients the BMI was not available. In all, 237 patients were classified as having normal weight $(37.2 \%), 320$ as overweight $(50.2 \%)$ and 80 as obese (12.6\%). Table 1 summarizes the clinical and pathological characteristics of the study population stratified by fat-density.

Patients in group 3 were significantly older. The median prostate volume was statistically different between the three groups but the differences were not clinically relevant. A clear significant association was seen between the fat-density groups and BMI, CFT and periprostatic fat. Figure 2 shows the correlation between BMI and the different fat measurements. The strongest correlation was seen between BMI and CFT (Pearson $r$ coefficient $=0.71, p<0.001$ ).

Logistic regression analysis revealed no statistically significant association between the different fat measurements and the risk of having high-risk disease (Table 2). Only age was significantly associated with increased risk of having a high-risk disease, however in the multivariable analysis (data not shown) this significance disappeared.

\section{Discussion}

The urologist and radiation oncologist will be confronted more frequently with obese patients having a localized PC. Although the association between obesity and the risk of PC risk is controversial $[4,17,18]$, a stronger link between obesity and increased risk for higher pathologic grade and higher rates of biochemical recurrence (BCR) compared with normal weight patients was seen in several studies [9, 19, 20]. Of note, all these studies were done in the USA. We conducted a study in The Netherlands where we evaluated 1,302 patients who underwent a radical prostatectomy. In that study BMI did not appear to have any prognostic value for BCR or worse pathologic features [21]. Same conclusions were drawn by another European study by Pfitzenmaier et al. [22]. In contrast with the USA, where $30 \%$ of the population is obese, only $9 \%$ to $14 \%$ of the European population was obese [23, 24]. Thereby, obese patients are less obese than the obese men in the USA and a relatively large proportion of the USA population consists of Afro-Americans who are more prone to be obese and more frequently have aggressive tumours compared with white men.

A question which may rise: are we measuring obesity on the right way? In most studies investigating obesity in relation to prostate aggressiveness and BCR, BMI is used as a criterion for general obesity. The most metabolic active fat however, is the abdominal visceral fat. WCF, as an indicator of abdominal obesity may be a better predictor of risk of more aggressive PC than BMI, especially in individuals with a lower BMI. Visceral fat is the most metabolic active fat and produce different kind of adipokines. Obesity is associated with increased levels of several adipokines and studies reported a link between the level of adipokines and aggressive PC [25-27].

A large study by the European Prospective Investigation into Cancer and Nutrition group concluded that once general obesity was adjusted for abdominal fat distribution it was positively associated with the risk of death. This association tended to be stronger among participants with a lower BMI [28]. In a large prospective cohort of 148,372 men, Pischon et al. [29] found that higher WCF was associated with increased risk of advanced PC and high-grade PC among individuals with lower BMI. The relative risk of advanced PC was 1.06 (95\% CI 1.01-1.10) per 5-cm-larger WCF. Same conclusions were drawn in a prospective Swedish study [30]. These data suggest that especially abdominal adiposity may be associated with an increased risk of advanced PC and WCF is a better way to measure obesity.

Visceral fat can affect both the lean and obese and is more metabolically active than subcutaneous fat. By measuring the WCF the discrepancy between thin outside 
Table 1 Baseline characteristics

Patients were stratified by fat density

$I Q R$ interquartile range

${ }^{a}$ Kruskal-Wallis-test

b $\chi^{2}$-Test

\begin{tabular}{|c|c|c|c|c|}
\hline & $\begin{array}{l}\text { Group } 1 \\
N=181 \\
<25 \text { percentile }\end{array}$ & $\begin{array}{l}\text { Group } 2 \\
N=363 \\
25-75 \text { percentile }\end{array}$ & $\begin{array}{l}\text { Group } 3 \\
N=181 \\
>75 \text { percentile }\end{array}$ & $p$ value \\
\hline \multicolumn{5}{|l|}{ Median (IQR) } \\
\hline Age, years & $64.0(59.0-68.0)$ & $66.0(61.0-70.0)$ & $68.0(63.0-71.0)$ & $<0.001^{\mathrm{a}}$ \\
\hline Follow up, months & $18.0(11.0-30.5)$ & $16.5(11.0-28.8)$ & $18.0(11.0-29.0)$ & $0.97^{\mathrm{a}}$ \\
\hline Prostate volume, $\mathrm{cm}^{3}$ & $37.0(30.0-44.0)$ & $34.3(28.0-41.0)$ & $34.0(27.8-40.0)$ & $0.02^{\mathrm{a}}$ \\
\hline Initial PSA, ng/ml & $8.4(6.3-12.2)$ & $8.5(6.3-11.7)$ & $9.0(6.9-12.5)$ & $0.20^{\mathrm{a}}$ \\
\hline BMI, $\mathrm{kg} / \mathrm{m}^{2}$ & $24.5(22.8-26.4)$ & $26.0(24.6-27.8)$ & $26.8(24.8-29.4)$ & $<0.001^{\mathrm{a}}$ \\
\hline Total periprostatic fat, $\mathrm{cm}^{2}$ & $23.7(19.3-25.9)$ & $31.3(28.0-34.5)$ & $40.5(36.9-43.5)$ & $<0.001^{\mathrm{a}}$ \\
\hline Fat density, $\%$ & $24.0(21.3-26.0)$ & $31.8(29.2-33.9)$ & $38.5(37.1-40.9)$ & \\
\hline Subcutaneous fat, $\mathrm{cm}$ & $3.9(3.2-4.7)$ & $4.7(3.9-5.5)$ & $5.1(4.1-6.1)$ & $<0.001^{\mathrm{a}}$ \\
\hline \multicolumn{5}{|l|}{$N(\%)$} \\
\hline \multicolumn{5}{|l|}{ WHO-classification } \\
\hline Normal weight & $88(57.9)$ & $109(33.5)$ & $40(25.0)$ & $<0.001^{\mathrm{b}}$ \\
\hline Overweight & $60(39.5)$ & $175(53.8)$ & $85(47.0)$ & \\
\hline Obesity & $4(2.6)$ & $41(12.6)$ & $35(19.3)$ & \\
\hline \multicolumn{5}{|l|}{ Clinical stage } \\
\hline $\mathrm{T} 1$ & $112(61.9)$ & $252(69.4)$ & $119(66.1)$ & $0.21^{\mathrm{b}}$ \\
\hline $\mathrm{T} 2$ & $69(38.1)$ & $111(30.6)$ & $61(33.9)$ & \\
\hline \multicolumn{5}{|l|}{ Grade } \\
\hline Low & $111(61.3)$ & $231(64.2)$ & $114(64.0)$ & $0.46^{\mathrm{b}}$ \\
\hline Intermediate & $70(38.7)$ & $129(35.8)$ & $64(36.0)$ & \\
\hline \multicolumn{5}{|l|}{ Ash risk group } \\
\hline Low & $69(38.1)$ & $141(39.2)$ & $67(37.4)$ & $0.96^{\mathrm{b}}$ \\
\hline Intermediate & $76(42.0)$ & $154(42.8)$ & 75 (41.9) & \\
\hline High & $36(19.9)$ & $65(18.1)$ & $37(20.7)$ & \\
\hline \multicolumn{5}{|l|}{ D'Amico risk group } \\
\hline Low & $72(39.8)$ & 145 (39.9) & $70(38.7)$ & $0.40^{\mathrm{b}}$ \\
\hline Intermediate & $99(54.7)$ & $200(55.1)$ & $95(52.5)$ & \\
\hline High & $10(5.5)$ & $14(3.9)$ & $12(6.6)$ & \\
\hline \multicolumn{5}{|l|}{ Lymph node dissection } \\
\hline Yes & $7(3.9)$ & $5(1.4)$ & $3(1.7)$ & $0.14^{\mathrm{b}}$ \\
\hline No & $174(96.1)$ & $358(98.6)$ & $178(98.3)$ & \\
\hline
\end{tabular}

(subcutaneous fat) and thick inside (visceral fat) cannot be made. A CT scan can distinguish between these two "layers". In our study we measured the visceral and subcutaneous fat on a CT to identify if one of these parameters is a better marker for tumour characteristics compared with BMI. Possible explanations for the lack of this correlation can be, first, there has been less enthusiasm for the use of brachytherapy in men with high-risk disease. These patients might be very well selected which can be an explanation for these negative findings. Second, the fat measurement was performed on one cross-sectional scan. Theoretically the accuracy of the fat measurement could be improved by measuring the fat content on more cross-sectional scans (volume measurement). However, in this study the selection bias of the brachytherapy patients is probable more important than the technique of fat measurement. Third, it is possible that the fat around the intra-abdominal organs are more metabolic active than the periprostatic fat. It would be interesting to measure the fat around the intraabdominal organs. However, it was not possible to measure the intra-abdominal fat distribution and body circumference at the level of the umbilicus. Fourth, it would be very interesting to correlate the BMI and fat density with clinical outcome like BCR or disease specific survival instead of pretreatment Gleason score, because these are better prognostic markers for PC aggressiveness. However, in this study the follow-up was much too short (mean $<20$ months) to evaluate these outcomes.

Our analysis showed a correlation between BMI and CFT and periprostatic fat-density. The correlation between 

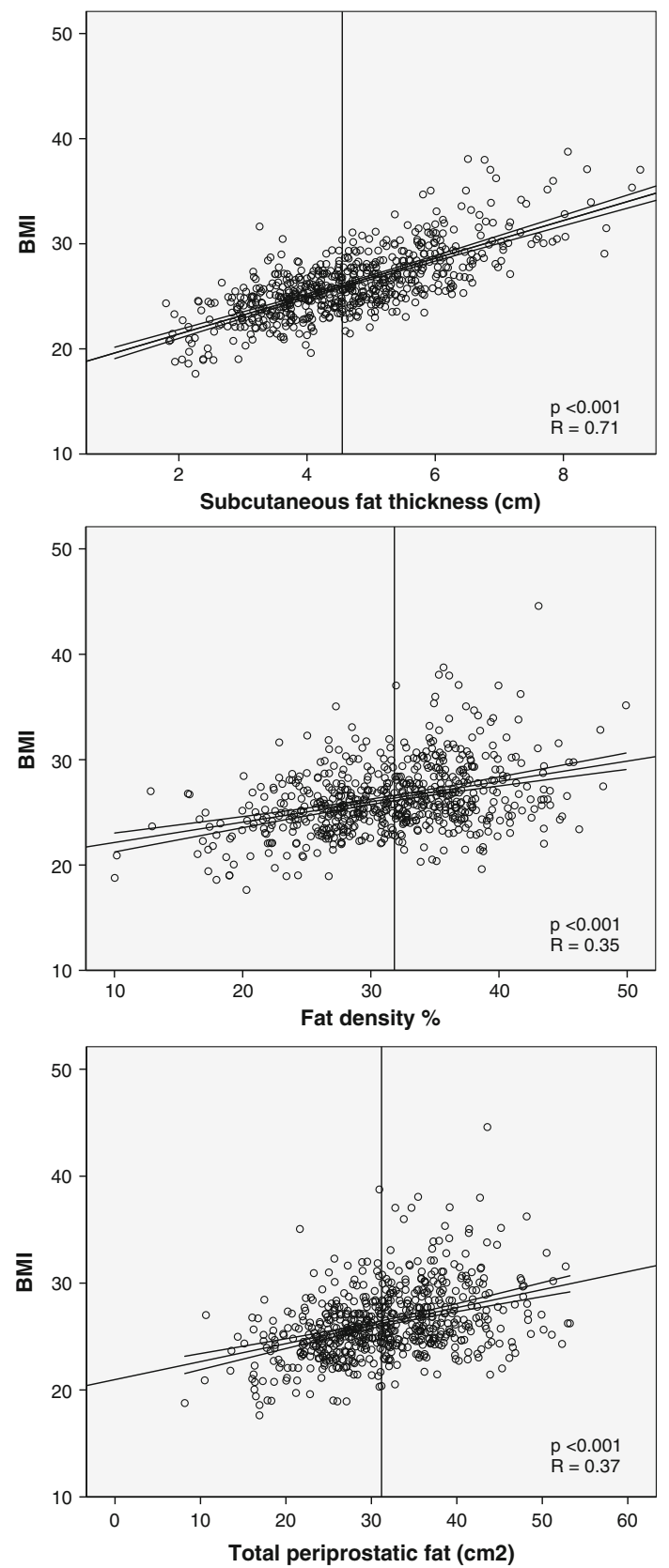

Fig. 2 Correlation between body mass index and different fat measurements. The linear regressive line is shown with $95 \% \mathrm{CI}$. The vertical line represents the median

BMI and CFT was much stronger than BMI and fat density. Interestingly, $31 \%$ of the patients with a normal BMI had a fat-density $>75$ percentile, compared with only $10 \%$ of the obese patients who had a fat-density $<25$ percentile of the fat-density. Thus, measurements on the outside of the body (BMI) do not always reflect the inner fat distribution measured on a CT scan. It is attractive to speculate that when this study was performed in a group of patients with more high-grade tumours, e.g. a group treated with external radiotherapy, these parameters could be a better prognostic
Table 2 Univariable logistic regression analysis of factors predicting high-risk disease

\begin{tabular}{|c|c|c|}
\hline Variable & Odds ratio $(95 \% \mathrm{CI})$ & $p$ value \\
\hline \multicolumn{3}{|l|}{ According to ash } \\
\hline Age & $1.07(1.03-1.11)$ & $<0.001$ \\
\hline Prostate volume & $1.00(0.98-1.02)$ & 0.68 \\
\hline BMI (continuous) & $0.97(0.92-1.03)$ & 0.37 \\
\hline \multicolumn{3}{|l|}{ BMI } \\
\hline$<25 \mathrm{~kg} / \mathrm{m}^{2}$ & 1 & \\
\hline $25-30 \mathrm{~kg} / \mathrm{m}^{2}$ & $0.80(0.53-1.21)$ & 0.29 \\
\hline$\geq 30 \mathrm{~kg} / \mathrm{m}^{2}$ & $0.51(0.24-1.06)$ & 0.07 \\
\hline Fat density (continuous) & $1.00(0.97-1.03)$ & 0.94 \\
\hline \multicolumn{3}{|l|}{ Fat density } \\
\hline Group 1 & 1 & \\
\hline Group 2 & $0.89(0.56-1.40)$ & 0.61 \\
\hline Group 3 & $1.05(0.63-1.76)$ & 0.85 \\
\hline Subcutaneous fat thickness & $0.96(0.85-1.10)$ & 0.56 \\
\hline Periprostatic fat area & $1.00(0.976-1.02)$ & 0.76 \\
\hline \multicolumn{3}{|l|}{ According to D'Amico } \\
\hline Age & $1.06(1.00-1.13)$ & 0.06 \\
\hline Prostate volume & $1.01(0.97-1.05)$ & 0.57 \\
\hline BMI (continuous) & $0.89(0.79-1.01)$ & 0.09 \\
\hline \multicolumn{3}{|l|}{ BMI } \\
\hline$<25 \mathrm{~kg} / \mathrm{m}^{2}$ & 1 & \\
\hline $25-30 \mathrm{~kg} / \mathrm{m}^{2}$ & $0.63(0.29-1.34)$ & 0.23 \\
\hline$\geq 30 \mathrm{~kg} / \mathrm{m}^{2}$ & $0.40(0.86-1.73)$ & 0.21 \\
\hline Fat density (continuous) & $1.00(0.95-1.06)$ & 0.94 \\
\hline \multicolumn{3}{|l|}{ Fat density } \\
\hline Group 1 & 1 & \\
\hline Group 2 & $0.69(0.30-1.59)$ & 0.39 \\
\hline Group 3 & $1.24(0.52-2.96)$ & 0.62 \\
\hline Subcutaneous fat thickness & $0.80(0.95-1.05)$ & 0.11 \\
\hline Periprostatic fat area & $1.00(0.96-1.05)$ & 0.93 \\
\hline
\end{tabular}

marker for tumour characteristics than BMI, especially in patients with a low BMI. However, further studies are needed to identify the real value of these fat measurements on $\mathrm{CT}$ as correlates with PC aggressiveness.

\section{Conclusion}

Periprostatic fat and fat-density were not of any value to predict $\mathrm{PC}$ aggressiveness in patients receiving brachytherapy. However, $31 \%$ of the patients with a normal BMI had a fat-density of $>75$ percentile of the periprostatic fat-density. More studies, including patients who have more aggressive PC, are needed to identify the true value of fat measurement on a CT as a correlate of PC aggressiveness and/or predictor of treatment failure. 


\section{Conflict of interest statement None.}

Open Access This article is distributed under the terms of the Creative Commons Attribution Noncommercial License which permits any noncommercial use, distribution, and reproduction in any medium, provided the original author(s) and source are credited.

\section{References}

1. Despres JP, Lemieux I (2006) Abdominal obesity and metabolic syndrome. Nature 444:881-887

2. Calle EE, Kaaks R (2004) Overweight, obesity and cancer: epidemiological evidence and proposed mechanisms. Nat Rev Cancer 4:579-591

3. Djavan B, Ravery V, Rocco B, Zlotta A, Brausi M, Margreiter M, Hammerer P, Kaisary A, Anagnostou T, Romics I, Dobronski P, De CO, Marberger M (2007) European study of radical prostatectomy: time trends in Europe, 1993-2005. BJU Int 100(Suppl 2):22-25

4. Engeland A, Tretli S, Bjorge T (2003) Height, body mass index, and PC: a follow-up of 950000 Norwegian men. Br J Cancer 89:1237-1242

5. Porter MP, Stanford JL (2005) Obesity and the risk of PC. Prostate 62:316-321

6. Wright ME, Chang SC, Schatzkin A, Albanes D, Kipnis V, Mouw T, Hurwitz P, Hollenbeck A, Leitzmann MF (2007) Prospective study of adiposity and weight change in relation to PC incidence and mortality. Cancer 109:675-684

7. Rodriguez C, Freedland SJ, Deka A, Jacobs EJ, McCullough ML, Patel AV, Thun MJ, Calle EE (2007) Body mass index, weight change, and risk of PC in the Cancer Prevention Study II Nutrition Cohort. Cancer Epidemiol Biomarkers Prev 16:63-69

8. Ma J, Li H, Giovannucci E, Mucci L, Qiu W, Nguyen PL, Gaiano JM, Pollak M, Stampfer MJ (2008) Prediagnostic body-mass index, plasma C-peptide concentration, and PC-specific mortality in men with PC: a long-term survival analysis. Lancet Oncol 9:1039-1047

9. Freedland SJ, Aronson WJ, Kane CJ, Presti JC Jr, Amling CL, Elashoff D, Terris MK (2004) Impact of obesity on biochemical control after radical prostatectomy for clinically localized PC: a report by the Shared Equal Access Regional Cancer Hospital database study group. J Clin Oncol 22:446-453

10. van Roermund JG, Witjes JA (2007) The impact of obesity on PC. World J Urol 25:491-497

11. Oka R, Miura K, Sakurai M, Nakamura K, Yagi K, Miyamoto S, Moriuchi T, Mabuchi H, Yamagishi M, Takeda Y, Hifumi S, Inazu A, Nohara A, Kawashiri M, Kobayashi J (2009) Comparison of WCF with body mass index for predicting abdominal adipose tissue. Diabetes Res Clin Pract 83:100-105

12. von Eyben FE, Mouritsen E, Holm J, Montvilas P, Dimcevski G, Suciu G, Helleberg I, Kristensen L, von Eyben R (2003) Intraabdominal obesity and metabolic risk factors: a study of young adults. Int J Obes Relat Metab Disord 27:941-949

13. Ash D, Flynn A, Battermann J, de RT, Lavagnini P, Blank L (2000) ESTRO/EAU/EORTC recommendations on permanent seed implantation for localized PC. Radiother Oncol 57:315-321

14. D'Amico AV, Whittington R, Malkowicz SB, Schultz D, Blank K, Broderick GA, Tomaszewski JE, Renshaw AA, Kaplan I, Beard CJ, Wein A (1998) Biochemical outcome after radical prostatectomy, external beam radiation therapy, or interstitial radiation therapy for clinically localized PC. JAMA 280:969-974
15. Bol GH, Kotte AN, van der Heide UA, Lagendijk JJ (2009) Simultaneous multi-modality ROI delineation in clinical practice. Comput Methods Programs Biomed 96:133-140

16. Yoshizumi T, Nakamura T, Yamane M, Islam AH, Menju M, Yamasaki K, Arai T, Kotani K, Funahashi T, Yamashita S, Matsuzawa Y (1999) Abdominal fat: standardized technique for measurement at CT. Radiology 211:283-286

17. Giovannucci E, Rimm EB, Liu Y, Leitzmann M, Wu K, Stampfer MJ, Willett WC (2003) Body mass index and risk of PC in U.S. health professionals. J Natl Cancer Inst 95:1240-1244

18. Kane CJ, Bassett WW, Sadetsky N, Silva S, Wallace K, Pasta DJ, Cooperberg MR, Chan JM, Carroll PR (2005) Obesity and PC clinical risk factors at presentation: data from CaPSURE. J Urol 173:732-736

19. Palma D, Pickles T, Tyldesley S (2007) Obesity as a predictor of BCR and survival after radiation therapy for PC. BJU Int 100:315319

20. Strom SS, Kamat AM, Gruschkus SK, Gu Y, Wen S, Cheung MR, Pisters LL, Lee AK, Rosser CJ, Kuban DA (2006) Influence of obesity on biochemical and clinical failure after external-beam radiotherapy for localized PC. Cancer 107:631-639

21. van Roermund JG, Kok DE, Wildhagen MF, Kiemeney LA, Struik F, Sloot S, van Oort I, Hulsbergen-van de Kaa CA, van Leenders GJ, Bangma CH, Witjes JA (2009) Body mass index as a prognostic marker for BCR in Dutch men treated with radical prostatectomy. BJU Int 104:321-325

22. Pfitzenmaier J, Pritsch M, Haferkamp A, Jakobi H, Fritsch F, Gilfrich C, Djakovic N, Buse S, Pahernik S, Hohenfellner M (2009) Is the body mass index a predictor of adverse outcome in $\mathrm{PC}$ after radical prostatectomy in a mid-European study population? BJU Int 103:877-882

23. Gast GC, Frenken FJ, van Leest LA, Wendel-Vos GC, Bemelmans WJ (2007) Intra-national variation in trends in overweight and leisure time physical activities in The Netherlands since 1980: stratification according to sex, age and urbanisation degree. Int $J$ Obes (Lond) 31:515-520

24. Ogden CL, Carroll MD, Curtin LR, McDowell MA, Tabak CJ, Flegal KM (2006) Prevalence of overweight and obesity in the United States, 1999-2004. JAMA 295:1549-1555

25. Michalaki V, Syrigos K, Charles P, Waxman J (2004) Serum levels of IL-6 and TNF-alpha correlate with clinicopathological features and patient survival in patients with $\mathrm{PC}$. $\mathrm{Br} \mathrm{J}$ Cancer 90:2312-2316

26. Saglam K, Aydur E, Yilmaz M, Goktas S (2003) Leptin influences cellular differentiation and progression in PC. J Urol 169:13081311

27. Strohmeyer D, Rossing C, Bauerfeind A, Kaufmann O, Schlechte H, Bartsch G, Loening S (2000) Vascular endothelial growth factor and its correlation with angiogenesis and p53 expression in PC. Prostate 45:216-224

28. Pischon T, Boeing H, Hoffmann K, Bergmann M, Schulze MB, Overvad K et al (2008) General and abdominal adiposity and risk of death in Europe. N Engl J Med 359:2105-2120

29. Pischon T, Boeing H, Weikert S, Allen N, Key T, Johnsen NF et al (2008) Body size and risk of PC in the European prospective investigation into cancer and nutrition. Cancer Epidemiol Biomarkers Prev 17:3252-3261

30. Wallstrom P, Bjartell A, Gullberg B, Olsson H, Wirfalt E (2009) A prospective Swedish study on body size, body composition, diabetes, and PC risk. Br J Cancer 100:1799-1805 